\title{
Introduction to How to Manage Student Consulting Projects
}

Babson College has been using an experiential learning approach since its founding in 1919, and it is a hallmark of how learning happens here. We pride ourselves on a learning model that emphasizes learning by doing and applying Babson's Entrepreneurial Thought and Action (ET\&A ${ }^{\mathrm{TM}}$ ) methodology to the issues that students are asked to solve while working effectively and collaboratively in teams. We have learned much about experiential learning in our journey, and this book is designed to share that learning with others who are or will be involved with managing and running student consulting project teams.

The use of student consulting teams, if done well, can make a big difference in student learning. Over the years, we have seen many practices at colleges and universities where student consulting projects are often assigned to students without providing the necessary structure and oversight to produce excellence in project effectiveness. Students are given the project assignment/topic with an emphasis on the final product. Often, however, there is too little attention paid to managing the comprehensive team process - from how the team can productively work together, to how to prepare to deal with interpersonal dynamics within the team, to helping students reflect and apply their learning from a project experience to their own personal and professional development. Students on teams frequently hear from their project advisors that they have little or no interest in dealing with issues of team dynamics or conflicts. The message seems to be: 'Just get the project done.' Further, on a very practical level, students often feel frustrated when everyone on the team receives the same grade, especially in those frequently encountered situations where some team members did not perform at an acceptable level and even hindered the team's overall performance. Fairness in assessing student performance should be a standard that we strive to achieve.

We continue to believe that the management of student consulting teams can be improved from current practices. As such, we will offer practical and tested strategies to help colleges and universities - and the project advisors that supervise such teams - to be even better. We also believe that the running of successful project teams is an intentional process that will benefit the many stakeholders who are involved in these efforts. 
During the final stages of completing this book, schools around the world were faced with major educational challenges due to the coronavirus pandemic. As a result, most students found themselves in virtual learning communities. In our student consulting projects, we implemented a number of strategies so that students and clients together could work virtually in completing their projects at a stressful time in our society when meeting face-to-face within teams or with clients could not happen. The role of the project advisor took on an even greater mission to be sure that the students would receive the academic and emotional support that these times required. Chapter 6 presents some ideas to help in managing teams virtually whether in good times or bad.

It is from our work with over 500 student consulting teams and almost that many project advisors, in addition to our learning from the extensive feedback that we have received along the way, that this book has been developed. It is our hope that our knowledge will help you in your own learning and will improve the way your student project teams are run.

\section{PURPOSE}

The primary purpose of this book is to highlight the key principles and tools needed by project advisors to manage student consulting teams in an academic setting. Project advisors can include faculty, staff, alumni, executives in residence, graduate students and others who are running and managing student teams working on consulting projects that are approximately one semester in length. These consulting projects can be part of an existing course or comprise the entire course itself. This book focuses on improving project performance by consulting teams working with client organizations, while also helping project advisors to develop the students on these teams both professionally and personally. The book also provides information for program administrators and deans that will help in the development and running of project-based learning using student consulting teams in either undergraduate or graduate programs.

\section{OUR PROJECT TEAM AND METHODOLOGY}

The authors of this book have over 45 years of combined experience managing student consulting team projects, much of which was acquired as a result of our work with the undergraduate Management Consulting Field Experience (MCFE) course at Babson College. Our team of authors consists of a senior professor who created the current approach and serves as the faculty director of the Babson undergraduate MCFE program; an executive in residence at Babson, who has been a project advisor for over 15 undergraduate and graduate consulting projects; and the associate director of experiential learning at 
Babson, who is central in selecting projects, clients and students for our undergraduate student consulting efforts and works closely with the faculty director of the MCFE program during the running of the projects each semester. We have collected data from faculty and staff colleagues in both the undergraduate school and the Olin Graduate School of Business, who also shared their experiences working with student consulting teams. In addition, we collected data on best practices from the perspectives of our past consulting clients who represent a range of businesses, from large global organizations to smaller start-up companies. Some of our clients represent very established businesses; two clients have histories that began in the $1600 \mathrm{~s}$ - one business represents one of the oldest working farms in the USA, while another is a fourteenth-generation family business that manufactures musical instruments that are used around the world. Finally, we examined best practices experienced and reported by project team members and project advisors.

\section{CHAPTER OUTLINE AND DESCRIPTIONS}

Chapter 1 describes our experience in managing student consulting teams at Babson College. We describe different approaches for managing student consulting teams in both our undergraduate and our graduate MBA programs. Regardless of the approach the reader chooses, the remaining chapters are designed to provide practical strategies for project advisors in managing student consulting teams and garnering the organizational support that may be needed. The reader is encouraged to adapt what we have written to fit the mission of your institution and the unique context of the types of projects that your school offers.

Chapter 2 provides a conceptual and practical model for the student consulting team process and introduces the importance of defining the core question that the client wants answered. Throughout the chapter, we describe major themes and best practices that we have learned from our experience and research with our student consulting teams and clients. Background information on key topics is discussed including confidentiality, the art of reflection and coaching. We also introduce two readings (found in their entirety in the Appendices) that have been written exclusively for this book-the first on solving the right problem for the client (Appendix 2A), and the second on the importance of diversity and inclusion (Appendix 2C). In addition, we discuss the benefits of using college resources, such as the college's research librarians.

In Chapter 3, we describe how project advisors, students and clients are recruited and selected as well as how consulting project topics are chosen. Roles and responsibilities of each of these stakeholders are discussed in 
addition to sample position descriptions for project advisors and a director of experiential learning.

Chapter 4 focuses on the actual hands-on management of student consulting teams in the beginning of a project. We look at the critical early steps in the first two weeks of a consulting assignment to prepare a team to meet its client and establish an Engagement Contract - the agreement between the project advisor, team members and client on the project questions to be answered by the team.

Chapter 5 presents guidelines for managing the team throughout the semester on topics including the running of team meetings, the roles played by team members during the duration of the project, strategies for managing the client relationship and the importance of feedback at all levels. We also explore key deliverables for student consulting teams including final project reports, Executive Summaries and 'Lessons Learned' reflection papers to capture learning from the students' perspectives. This chapter also provides a comprehensive set of guidelines for conducting professional client-facing consulting presentations, along with a checklist for use by student teams. (An informative article on preparing team members for conducting the oral presentations to clients is introduced in this chapter and can be found in full in Appendix 5A.)

Chapter 6 presents strategies for the evaluation of projects, students and the overall consulting program. We discuss learning outcomes and why the traditional satisfaction survey by itself, and done at the conclusion of a project or course, is not always a worthwhile activity. We also show a summary feedback graphic from a client who conducted an in-depth analysis of the longer-term impact of Babson student consulting teams on the client's business. We revisit the reflection process and discuss the learning benefits gained from analyzing student reflection papers. We also present and discuss a sample evaluation form for collecting client feedback. Finally, as we discussed earlier, we present some strategies for success in managing teams virtually, specifically looking at a case where the project advisor was located 3,000 miles away from the student team. 
Joseph R. Weintraub, George A. Lee, and Arline A. MacCormack - 9781789907834 Downloaded from PubFactory at 04/26/2023 06:02:59AM 